\title{
The role of perceived satisfaction and the built environment on the frequency of cycle-commuting
}

\author{
Tomás Echiburú \\ Pontificia Universidad Católica de Chile and \\ Center for Sustainable Urban Development \\ tomas.echiburu@uc.cl \\ Juan Carlos Muñoz \\ Pontificia Universidad Católica de Chile and \\ Center for Sustainable Urban Development \\ jcm@ing.uc.cl
}

\author{
Ricardo Hurtubia \\ Pontificia Universidad Católica de Chile and \\ Center for Sustainable Urban Development \\ rhurtubia@uc.cl
}

\begin{abstract}
Understanding how several street attributes influence the frequency of cycle commuting is relevant for policymaking in urban planning. However, to better understand the impact of the built environment on people's choices, we must understand the subjective experience of individuals while cycling. This study examines the relationship between perceived satisfaction and the attributes of the built environment along the route.

Data was collected from a survey carried out within one district of Santiago's central business district $(\mathrm{N}=2,545)$. It included sociodemographic information, origin-destination and route, travel behavior habits, and psychometric indicators. Two models were estimated. The first, a satisfaction latent variable model by mode, confirms previous findings in the literature, such as the correlation between cycling and a more enjoyable experience, while adding some new findings. For instance, satisfaction increases with distance and the number of trips per week. The second is a hybrid ordered logit model for cycle commuting frequency that includes satisfaction, through a structural equation, that shows this latent variable plays a significant role in travel behavior.

The presence of buses along the route decreases cycling satisfaction and frequency, while the trip length and the availability of cycle paths has the opposite effect for male and female cyclists. These results allow us to understand the main factors that deliver satisfaction to cyclists and therefore induce frequent cycle commuting. Overall, our study provides evidence of the need for policymakers to focus their strategies so as to effectively promote cycling among different types of commuters.
\end{abstract}

\section{Article history:}

Received: June 17, 2020

Received in revised form:

September 26, 2020

Accepted: September 28, 2020

Available online: February 2,

2021

\section{Introduction}

Many cities around the globe have begun to promote cycle-commuting as an effective tool to reduce the negative impacts of motorized transport on the environment and people's health, while simultaneously improving the quality of life of their inhabitants (Buehler \& Pucher, 2011; Ogilvie, Egan, Hamilton,

Copyright 2021 Tomás Echiburú, Juan Carlos Muñoz \& Ricardo Hurtubia http://dx.doi.org/10.5198/jtlu.2021.1826

ISSN: 1938-7849 | Licensed under the Creative Commons Attribution - Noncommercial License 4.0

The Journal of Transport and Land Use is the official journal of the World Society for Transport and Land Use (WSTLUR) and is published and sponsored by the University of Minnesota Center for Transportation Studies. 
\& Petticrew, 2004). By enabling a shift from driving to cycling, cities can reduce their greenhouse emissions and improve local air quality (Macmillan et al., 2014) while helping to alleviate congestion and improving mobility for large groups in their population, including non-cyclists.

Increasing cycling rates have also been demonstrated to have substantial health benefits that outweigh the risk of being exposed to traffic and air pollution (de Hartog, Boogaard, Nijland, \& Hoek, 2010). Currently, not only Amsterdam or Copenhagen but bigger cities like London, Paris or New York, are heavily investing to induce people to commute by bicycle more often, significantly increasing the length and quality of their cycling networks in the last 20 years (Aldred \& Dales, 2017; Buehler \& Dill, 2015; Pucher, Buehler, \& Seinen, 2011). Nevertheless, there is a lack of evidence from cities in developing countries, especially in the global south, to help to achieve the best strategies that would promote cycle-commuting. This is the case of Santiago, the capital of Chile, where bicycle usage has been rising up quite significantly but there is not enough research on the field to understand the reasons motivating this modal shift and how to further encourage it.

The impact of the built environment on different travel patterns has been widely researched. Most of the findings confirm a strong correlation between urban form and car dependency or the usage of sustainable transport modes (Cervero \& Duncan, 2003; Cui, Mishra, \& Welch, 2014; Handy \& Xing, 2011). The influence of perceptions and attitudes towards cycling or bicycle usage has also been studied, mostly to understand the deterrents that keep people away from cycling (Dill \& McNeil, 2013).

Despite the abundant literature relating bicycle usage with the built environment, there are still some aspects that have not been deeply researched. The majority of the literature focuses on cycling for general purposes, rather than specifically on commuting. When analyzing the attributes of the built environment, most of the studies found in the literature refer to the surrounding neighborhood at the origin of the trip (Cervero, Sarmiento, Jacoby, Gomez, \& Neiman, 2009; Sallis et al., 2013). More recently, some authors have also studied these conditions at the destination (Oliva, Galilea, \& Hurtubia, 2017). Nevertheless, very few have analyzed the statistical impact of the route attributes in the cycling commute frequency or propensity to cycle in general.

When it comes to the link between the built environment and subjective perceptions of users, there are a few studies that attend to this relationship, mostly analyzing the difference of measurable aspects of the built environment and how they are perceived. For instance, Ma and Dill (2015) analyzed the difference between the actual presence of cycle infrastructure in a neighborhood and the perception of availability of such infrastructure among people. There is also the work on Level of Traffic Stress (LTS), which is trying to provide a consistent way to estimate cycling comfort related to route characteristics (Lowry, Furth, \& Hadden-Loh, 2016) with relatively low resources, although this methodology has some limitations as Wang, Palm, Chen, Vogt, and Wang (2016) conclude that LTS criteria may not be useful for cities looking to prioritize infrastructure improvements for specifically increasing commuter cycling, but instead, it is a valid measure for households' propensity to cycle. To the best of our knowledge, there are no studies evaluating how the built environment along the route influences bicycle users' perceptions, and how this relates to modal choice and cycling frequency. Furthermore, very few of the aforementioned studies have been conducted in cities from developing countries, where cycling still represents a small part of the modal split (below $5 \%$ in most large cities), although increasing quickly, which offers an attractive research opportunity.

In this paper we present a model for estimating cycle-commuting frequency, incorporating a latent variable of perceived satisfaction which is a function of built environment attributes of the commuter's route, therefore making it a perceptual latent variable. This type of model specification is not frequent in the literature, despite its theoretical and practical convenience (Bahamonde-Birke, Kunert, Link, \& Ortúzar, 2017). Unlike attitudinal latent variables, which are individual-specific, perceptual latent 
variables are also a function of alternative attributes and, therefore, allow to understand not only how changes in the attributes affect utility and behavior, but also other intermediary (but still relevant) latent constructs such as perceived safety (Gutiérrez, Hurtubia, \& Ortúzar, 2020; Rossetti et al., 2019), quality (Palma et al., 2016) or comfort (Guevara, Tirachini, Hurtubia, \& Dekker, 2020).

To reach a correct specification of the latent variable equation for cyclists, we first estimate an independent model of perceived satisfaction for each transport mode. Then, we estimate a model for cyclecommuting frequency where satisfaction is included as a latent variable and estimated simultaneously.

We identify relevant variables correlating with cycling frequency in the city of Santiago. Most of them confirm previous findings reported in the literature while others reveal new factors that might be determinant to promote bicycle usage. The presence of cycle paths or the trip length, for instance, does not have the same effect on male and female cyclists.

The article is organized as follows: Section 2 presents a brief literature review of previous efforts to understand the impact of the built environment, subjective perceptions, and perceived satisfaction on travel behavior; Section 3 describes the methods chosen for the analysis, explaining the specification of the estimated models; Section 4 presents a description of the case study and data collection process; Section 5 shows the results obtained, Section 6 offers a discussion about the results, and Section 7 presents the main conclusions.

\section{$2 \quad$ Literature review}

Many factors influence a person's decision to cycle. These factors can be categorized as objective or environmental, subjective or perceived, and socio-demographic (Dill \& Voros, 2007). This literature review explores the role of the built environment and street design attributes; the subjective perceptions and personal attitudes; and perceived satisfaction, as factors that could encourage (or discourage) more people to commute by bicycle and to do so regularly.

\subsection{Influence of the built environment and street design}

Ortúzar, Iacobelli, \& Valeze (2000) conclude from their analysis of Santiago, that trip distance is a fundamental element to predict the demand of a cycle network. This is consistent with several studies finding that a longer commute distance has a negative impact on cycling (Cervero \& Duncan, 2003; Cui et al., 2014; Handy \& Xing, 2011). Thus, a strong correlation seems to exist between modal choice and the urban form and how activities are located within the city, determining travel distances. Like distance, the slope of the route has been also identified as a deterrent in cycle-commuting frequency (Oliva et al., 2017) although this seems to be the case only above some thresholds (Cervero et al., 2009, found it to be significant only when slope is above $3 \%$ ).

Having more bicycle infrastructure has been found to correlate with a higher share of cyclists (Buehler \& Dill, 2015; Heinen, van Wee, \& Maat, 2009; Krizek, Barnes, \& Thompson, 2009), and people tend to say that they would cycle more often if there were more bike lanes on their route (Dill \& Voros, 2007). Moreover, the presence of bicycle infrastructure increases the willingness to explore the bicycle as a transport mode (Gutiérrez et al., 2020). This is consistent with the Akar and Clifton (2009) study on a university campus that found the lack of bike lanes to be the most important factor to keep students from cycling. The presence of en-route facilities has shown to be a cost-effective measurement to increase the bicycle modal split in Great Britain (Wardman, Tight, \& Page, 2007). However, Moudon et al. (2005) report that the presence of more bicycle infrastructure does not have a significant effect on cycling levels. More research on this issue is needed in order to understand the real implications 
of building different types of infrastructure for cyclists.

Apart from the existence of bicycle infrastructure on the route, Stinson and Bhat (2003) found that cyclists prefer routes with more continuous facilities and that they have a negative perception of a bike lane ending abruptly (Stinson \& Bhat, 2005). This is the experience of most cyclists in cities with fragmented networks. Just one or more segments on the route without dedicated space may be a deterrent for some people to cycle-commute. When there is no continuity on the bike infrastructure, people are forced to fill the gap by riding either between traffic or on the sidewalks. The study by Akar and Clifton (2009) states that cyclists prefer streets with fewer lanes, lower volumes of traffic, slower speeds, and without parked cars. Recent studies have evaluated the relationship between the built environment and cycling frequency (Cervero et al, 2009; Oliva et al., 2017) focusing on the attributes of the neighborhood and surroundings, but not on the route itself. Thus, there is an opportunity to contribute with an analysis of the chosen route attributes by the commuters.

To date, attributes of street design have been evaluated mostly with stated preference techniques (Hunt \& Abraham, 2007; Rossetti, Saud, \& Hurtubia, 2019). There are some studies of route choices that evaluate the effectiveness of different kinds of facilities with revealed preferences (Broach, Dill, \& Gliebe, 2012), but they generally rely on GPS data from small samples (Pritchard, 2018). Consequently, this procedure has some limitations in order to extract conclusions that can be generalized.

\subsection{The role of subjective perceptions and latent variables in cycling}

Several studies and experts have reported a number of subjective factors that keep people from cycling. Some of them are related to the perception of danger, risk related to bad traffic, bad weather, personal factors, lack of daylight, inconvenience, or lacking sufficient fitness (Dickinson, Kingham, Copsey, \& Hougie, 2003; Gatersleben \& Appleton, 2007; Gatersleben \& Uzzell, 2007; Gutiérrez et al., 2020; Noland \& Kunreuther, 1995; Stinson \& Bhat, 2004). All of these can be barriers for people to get on a bicycle and, while some of them are a result of the interpretation of observable context attributes, they are also far from being objective: they reflect people's feelings and fears.

The use of latent variables to explain cyclist behavior or preferences is relatively new and hasn't reached its full potential yet. Furthermore, most of these studies dwell on the field of attitudinal latent variables (Fernández-Heredia, Monzón, \& Jara-Díaz, 2014; Gutierrez et al., 2020; Muñoz, Monzón, \& Daziano, 2016). For instance, Fernández-Heredia et al. (2014) identified four latent variables explaining the intention to cycle, namely: convenience, pro-bike, physical determinants and exogenous restrictions. Their main conclusion is that convenience (flexible, efficient) and exogenous restrictions (danger, vandalism, facilities) are the most important elements to understand the attitudes towards the bicycle. Among the few cases applying perceptual latent variables, there is a study conducted in Vitoria-Gasteiz (Muñoz, Monzón, \& López, 2016) which found that safety and comfort were not significant barriers for all commuters, while perceived social pressure is a relevant factor in transition cities. Another research from Santiago (Rossetti, Guevara, Galilea, \& Hurtubia, 2018), used stated preferences to determine the influence of safety perception on route choice, finding heterogeneous preferences, with some users putting a significantly higher weight on perceived safety than others.

A study conducted in Sydney (Rissel, Crane, Wen Greaves, \& Standen, 2016) found that people who walk or ride a bicycle for commuting were significantly more likely to report their experience as enjoyable compared to those who drive or use public transport. This is partly consistent with another study from the United States (Morris \& Guerra, 2015) which states that cyclists, car passengers, and car drivers enjoy their travel more than transit users. This may imply that perception of satisfaction, or enjoyment, plays a significant role in route and modal decision, and it appears to be relevant to address the relation with the built environment and street amenities. A recent study from Ma and Dill (2015), 
investigates the association between the objectively measured built environment, its stated perception and its influence on cycling propensity and frequency. Although, to the best of our knowledge, none of the aforementioned studies evaluate the effect of objective attributes along the route in subjective perception and how this relates to cycling frequency, applying latent variables through structural equations.

\subsection{Perceived satisfaction and travel behavior}

One key element of subjective perception that plays an important role in cycling behavior is trip satisfaction. A study conducted by Olsson, Gärling, Ettema, Friman, \& Fujii (2013) found that satisfaction with the work commute contributes to overall happiness. Possible explanatory factors include desirable physical exercise from walking and biking, as well as short commutes providing a buffer between the work and private spheres.

De Vos (2019) suggests that travel satisfaction might induce modal choice more than the opposite, and the effect of travel mode on travel satisfaction seems partly mediated by attitudes. Although De Vos, Schwanrn, Van Acker, and Witlox (2019) recognize that active travel is often associated with the highest levels of travel satisfaction, also argued that the effect of chosen mode on travel satisfaction might be overestimated, and that it is not so much the travel mode itself that affects satisfaction, but whether the chosen travel mode is consistent with attitudes towards that mode.

Willis, Manaugh, and El-Geneidy (2013) found that cyclists are more satisfied with their commute than other mode users, and detected a correlation between perceived satisfaction and attitudes such as being a "cyclist enthusiast." However, the expected relationship between distance, slope, elements of the built environment and trip satisfaction was not found. In another study that attempts to measure the relation between the built environment and satisfaction, Ye and Titheridge (2017) evaluated the effect of built environment attributes at the origin and destination of the trip, finding counterintuitive results. Surprisingly, a car-dependent environment (i.e., suburbs with few bus transit services and less connected streets) at the home location was associated with more bike and e-bike use for commuting, and a cardependent environment at the workplace destination was associated with more walking for commuting.

Therefore, the relationship between the built environment and perceived satisfaction is still understudied and requires further research. Besides, to the best of our knowledge there are no studies focusing on the built environment along the route that have found a relationship with perceived satisfaction.

Regarding the methods to evaluate travel satisfaction, Abou-Zeid. Witter, Bierlaire, Kaufmann, and Ben-Akiva (2012) measured the effect of switching from car commute to public transport asking for reliability, flexibility, convenience, comfort, and overall service quality. Likewise, Ettema et al. (2011) develops a scale to measure satisfaction called "satisfaction with travel scale" (STS) considering, as well, factors such as time travel and reliability, the emotions that travel experience generates, and the overall quality of such experiences. Both studies offer a reference to measure perceived satisfaction, although neither of them focuses on the cycle-commuting experience.

\section{Case study and data collection}

The bicycle modal split in Santiago de Chile grew up from 2\% to 4\% in eleven years, between 2001 and 2012 according to the official origin-destination survey (SECTRA, 2015). A study from the Ministry of Transport (SECTRA, 2013), estimated a growth rate of $20 \%$ per year in central districts that built cycle infrastructure. Since our study is focused on bicycle commuting, the survey was applied in the municipality of Providencia, which contains a large portion of Santiago's central business district, and has the 
highest floating population in Santiago de Chile, receiving more than 1.5 million people every day for working and studying. According to a recent survey (MIDESO, 2017), Providencia has the highest participation of cycle-commuting ( $9 \%$ ) within the central and pericentral municipalities of Santiago, and keeps growing. As an urban body, Santiago has no metropolitan government. Instead it is divided into 39 municipalities, or 48 if you add the suburbs (Fuentes \& Pezoa, 2018). Bicycle infrastructure is mostly funded at this level, affecting its continuity and network coherence. This lack of central coordination and planning is noticeable in the fragmented network of cycling infrastructure that the city has (Figure 1). Despite this fact, some municipalities around the city center have invested in cycling infrastructure in the last decade, making an effort to coordinate with the surrounding neighbors. That's the case of Las Condes, Santiago, and Providencia which are among the wealthiest in the city.

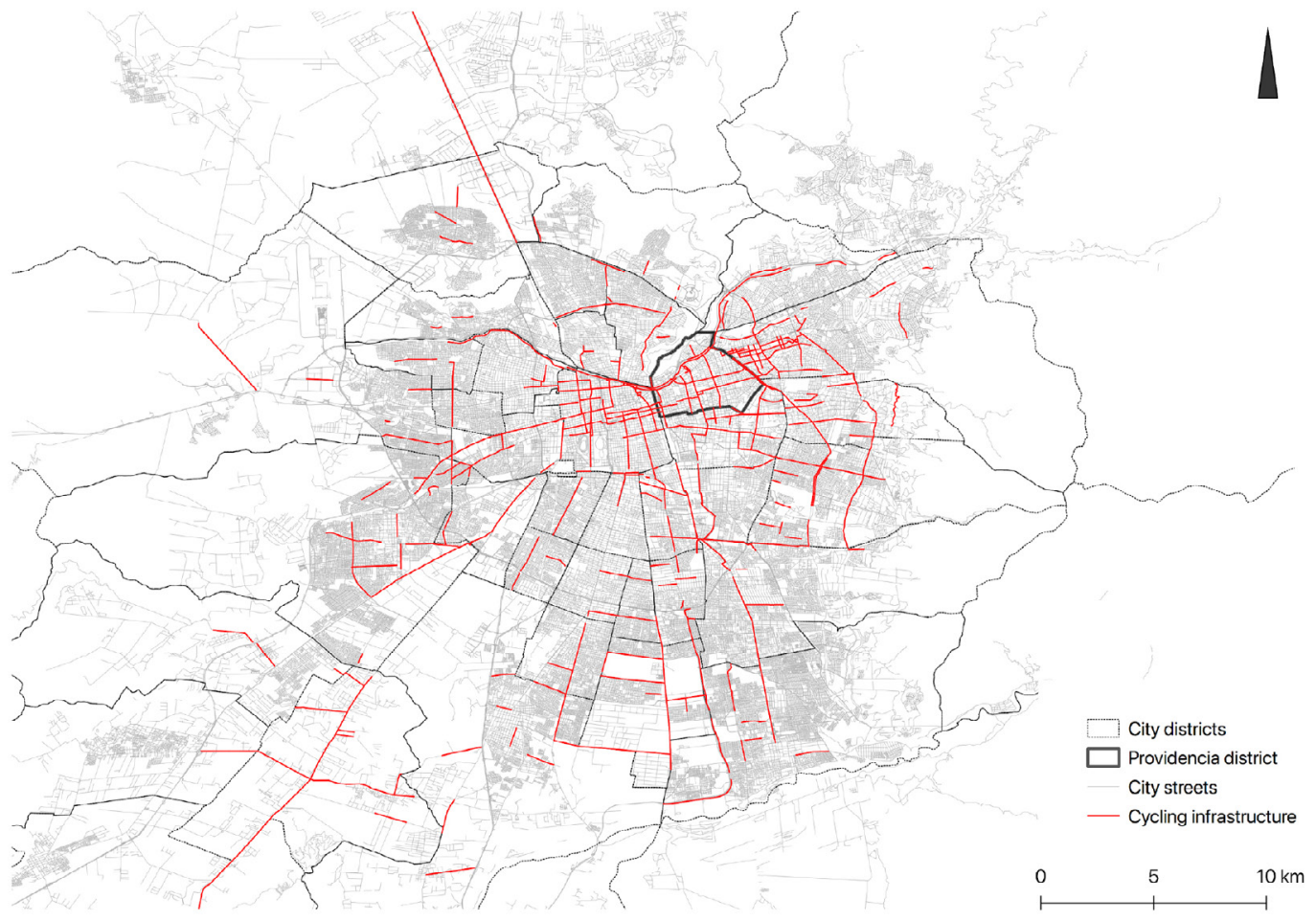

Figure 1. Santiago's cycling infrastructure in 2019

\subsection{Survey}

A travel survey was designed to ask about the habitual commuting route to travelers from different modes. The survey considered 30 questions divided into three parts and was designed to be completed in 7 to 10 minutes.

The first part consisted of socio-demographic questions such as age, gender, level of education and occupation, among others. A second part asked about the one-way trip to the respondent main activity on a weekly basis, selecting one or more modes of transport for each day. It also includes origin and destination, and main streets along the route. It is important to highlight the way we ask for the main streets along the route, in order to construct a proxy of the actual commuters route that allows us to evaluate the attributes of the built environment on them. The respondents were invited to select, from a 
list, the streets that were part of their most common route.

The third part looked into the perceived traveling experience and the main barriers to commuting by bicycle, including psychometric indicators to evaluate how the commuting experience is perceived. In particular, we asked about the perception of the trip in four dimensions that should be correlated to satisfaction: expeditious, pleasant, safe and gratifying. While the first three are clearly different (even orthogonal) aspects (e.g.,a trip can be expeditious but unpleasant, or safe but unpleasant), the gratifying indicator attempts to measure the overall perception of the trip and is expected to be strongly correlated with satisfaction (if not the same thing). The selection of these psychometric indicators to measure satisfaction is loosely based on other indicators reported in the literature for the same purpose (e.g., Ettema et al., 2011; Abou Zeid et al., 2012)

The survey was conducted in December 2018. This period corresponds to the beginning of the summer. In order to maximize our respondents and get cyclists and non-cyclists commuters, we divide our fieldwork into four steps. A total of 2,545 observations were collected, some of them by intercepting pedestrians, cyclists and public transport users $(1,120)$; another portion from social media and mailing $(1,058)$; a few by delivering flyers in traffic lights $(182)$; and lastly from municipality workers (185) of Providencia.

The origins and destinations of the respondents are concentrated in Providencia and surrounding boroughs (Figure 2). Most respondents (93\%) declared to pass through the district in their commuting. This was due to the recruiting process of the survey, which was explicitly oriented to users commuting to or through Providencia, in order to facilitate the estimation of the chosen route from a list of main streets displayed in the survey.

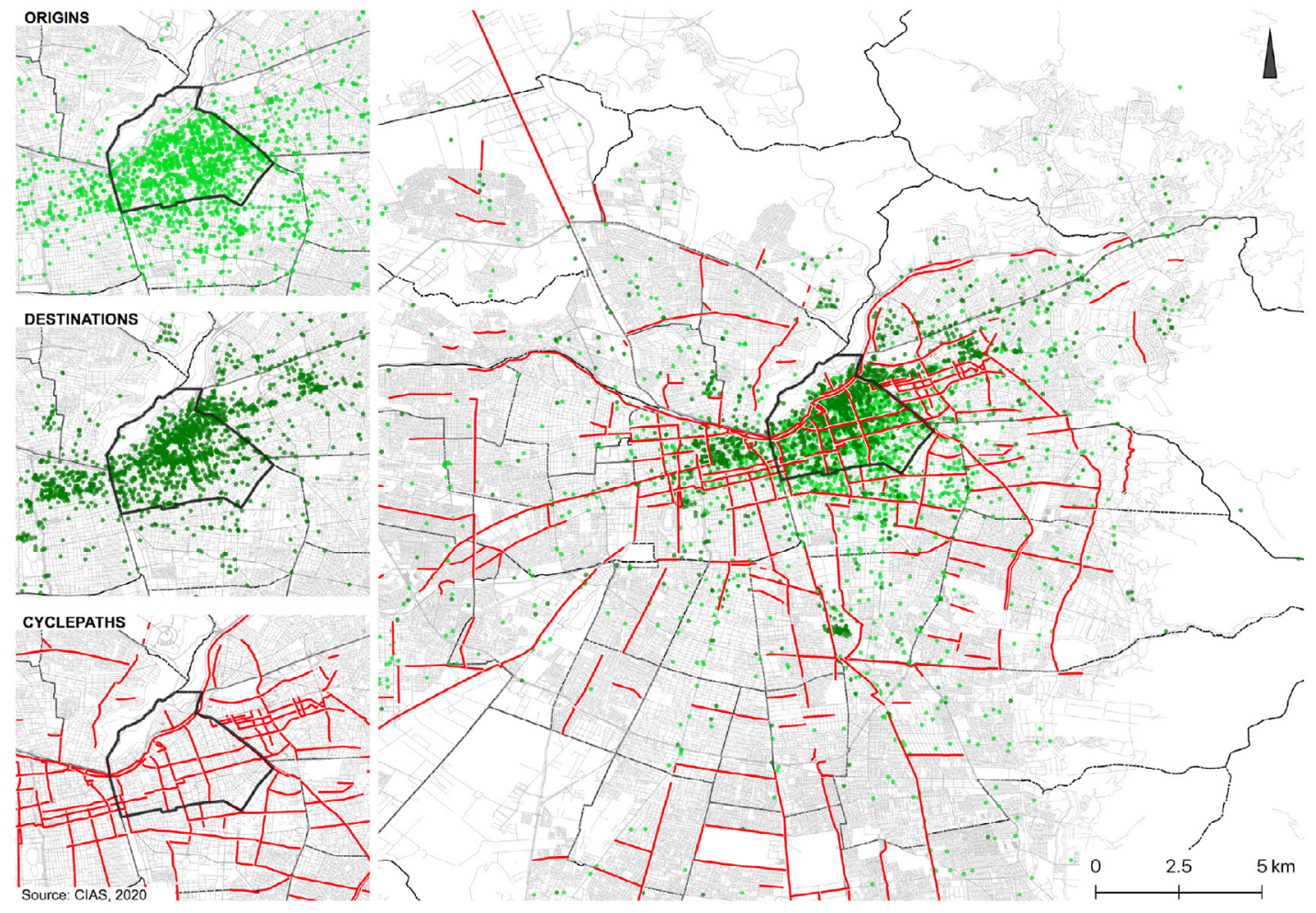

Figure 2. Sample's origins and destinations in the context of Santiago city 
A preliminary descriptive analysis of the sample distribution (Table 1) shows that $44 \%$ of the respondents were female, which may imply a slight gender bias. The average age is 37 years old and $84 \%$ had completed higher education, indicating that this segment of the population is over-represented. Regarding household characteristics, on average there are 0.8 cars and 1.8 bicycles per household in the sample.

In reference to travel purposes, $81 \%$ of respondents declared it to be work and $9 \%$ study, with the remaining 10\% distributed among shopping, healthcare and other purposes. Considering the aim of this study, we have excluded the latter $10 \%$ from the estimation database to focus on commuter's trips on their way to work -or study-place. Since travel distance is a key variable in our model specification, we have also excluded the observations that did not report an origin or destination. Thus, our final sample for the modelling process has 2016 observations. The majority of commuters travel alone (83\%) and the average trip distance is $7.5 \mathrm{~km}$, while the median is $5.5 \mathrm{~km}$. Most people who commute by bicycle (55\%) ride between 2 to $6 \mathrm{~km}$ on the way to work every day, while people who have longer trip distances, over $8 \mathrm{~km}$, are most likely to be car drivers or public transport users.

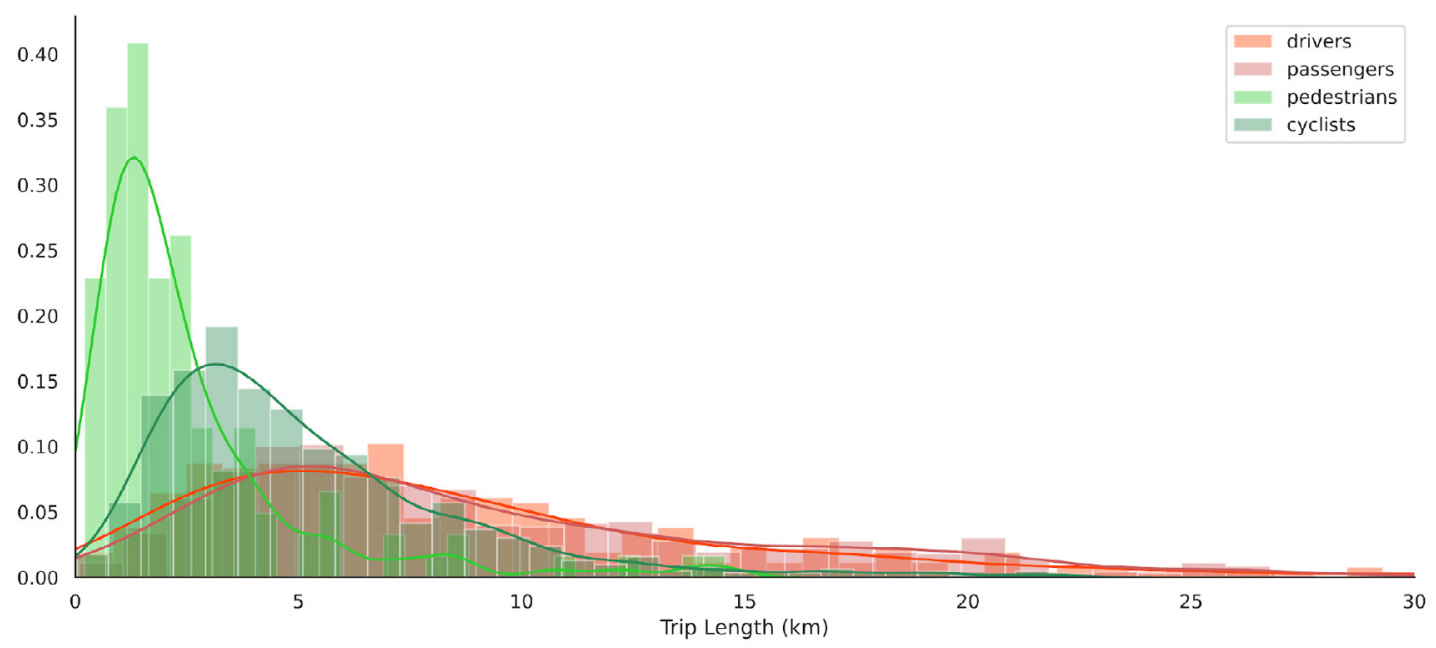

Figure 3. Trip length histogram by transport mode

Regarding the modal split for all the trips reported in the survey (Table 2), most of the trips are made by public transport (34\%) followed by the bicycle (26\%), car (22\%) and walking (16\%). In the sample, the bicycle appears with significantly higher participation in comparison to the last official survey (SECTRA, 2015) where the bicycle trips are only 4\%. However, the use of the bicycle has increased strongly since the data for that survey was gathered. A more recent survey (MIDESO, 2017) shows that for commuting purposes the participation of the bicycle is around $9 \%$ for trips originated in Providencia. All observers agree that bicycle trips have kept growing since then. Still, our sample clearly over-represents bicycle trips and users, which suits well the main objectives of the study. Since we don't want to estimate modal splits, our sample does not need to be representative in terms of mode choice. It does require, however, to have a large-enough number of observations per transport mode, with sufficient socioeconomic diversity within users.

Since we want to estimate the level of satisfaction associated with the use of a particular mode of transport, we need to identify the main transport mode for each respondent. For this, we specify a dummy variable as follows: 
$M_{n m}=1$ if $t_{n m}>t_{n m^{\prime}\left(\forall m^{\prime} \neq m\right)}$

where $t_{n m}$ is the number of weekly trips by the individual $n$ in mode $m$. Therefore, the dummy $M_{n m}$ takes the value of 1 , when the number of trips made by the individual $n$ in mode $m$ exceeds those made in any other mode. Using equation (1) we can divide our sample into 107 pedestrians (5\%), 693 public transport users (34\%), 293 car users (15\%), and 820 cyclists (40\%). There were 193 observations (9\%) which could not be assigned to any mode, either because they commute in a different mode (ej: Taxi) or because they use more than one mode during the week and there is a tie between them.

Among cyclists, $58 \%$ are solely bicycle users, and $87 \%$ ride a bicycle for at least $70 \%$ of their trips. Regarding the other modes, $56 \%$ of car drivers, $64 \%$ of Public transport passengers and $54 \%$ of pedestrians commute exclusively on their preferred mode, while $86 \%, 87 \%$ and $82 \%$ do it in more than $70 \%$ of their trips, respectively. The last two columns of Table 1 show the sample characteristics for cyclists and non-cyclists. We see that, besides gender, trip length and number of bicycles at home, bicycle users are quite similar to the users of other transport modes.

Table 1. Descriptive analysis

\begin{tabular}{|c|c|c|c|c|}
\hline Variables & $\mathbf{N}$ & $\%$ & Bicycle (\%) & Other modes (\%) \\
\hline Gender & 2545 & 100 & 100 & 100 \\
\hline Male & 1417 & 56 & 65 & 48 \\
\hline Female & 1111 & 44 & 35 & 51 \\
\hline N/A & 17 & 1 & 0 & 1 \\
\hline Age group & 2545 & 100 & 100 & 100 \\
\hline $18-30$ & 856 & 34 & 34 & 33 \\
\hline $31-40$ & 925 & 36 & 42 & 32 \\
\hline $43-50$ & 465 & 18 & 17 & 19 \\
\hline $51-60$ & 208 & 8 & 5 & 11 \\
\hline $61-99$ & 91 & 4 & 2 & 5 \\
\hline Education & 2545 & 100 & 100 & 100 \\
\hline School & 418 & 16 & 11 & 21 \\
\hline Technical & 251 & 10 & 8 & 12 \\
\hline Undergraduate & 1262 & 50 & 56 & 44 \\
\hline Postgraduate & 614 & 24 & 26 & 23 \\
\hline Occupation & 2545 & 100 & 100 & 100 \\
\hline Student & 254 & 10 & 8 & 12 \\
\hline Employee & 1652 & 65 & 64 & 65 \\
\hline Self employed & 514 & 20 & 23 & 17 \\
\hline Housecare & 18 & 1 & 0 & 1 \\
\hline Unemployee & 54 & 2 & 3 & 2 \\
\hline Retired & 27 & 1 & 1 & 2 \\
\hline Other & 26 & 1 & 1 & 1 \\
\hline Trip Purpose & 2545 & 100 & 100 & 100 \\
\hline Work & 2078 & 82 & 83 & 80 \\
\hline Study & 248 & 10 & 8 & 12 \\
\hline Strolling & 61 & 2 & 3 & 2 \\
\hline Shopping & 49 & 2 & 2 & 2 \\
\hline
\end{tabular}




\begin{tabular}{lrrrr}
\hline Variables & $\mathbf{N}$ & $\mathbf{\%}$ & Bicycle (\%) & Other modes (\%) \\
\hline Healthcare & 32 & 1 & 1 & 2 \\
Other & 77 & 3 & 3 & 2 \\
Trip Distance & $\mathbf{2 2 7 9}$ & 100 & 100 & 100 \\
\hline$<2 \mathrm{~km}$ & 259 & 11 & 13 & 10 \\
$2-4 \mathrm{~km}$ & 516 & 23 & 32 & 14 \\
$4-6 \mathrm{~km}$ & 491 & 22 & 24 & 19 \\
$6-8 \mathrm{~km}$ & 301 & 13 & 13 & 13 \\
$>8 \mathrm{~km}$ & 712 & 31 & 18 & 44 \\
Kids at home & $\mathbf{2 5 4 5}$ & 100 & 100 & 100 \\
\hline 0 & 1571 & 59 & 65 & 59 \\
1 & 552 & 22 & 21 & 22 \\
2 or more & 422 & 19 & 14 & 19 \\
Cars at home & $\mathbf{2 5 4 5}$ & 100 & 100 & 100 \\
\hline 0 & 770 & 30 & 34 & 27 \\
1 & 1280 & 50 & 49 & 52 \\
2 or more & 495 & 20 & 17 & 21 \\
Bicycles at home & $\mathbf{2 5 4 5}$ & 100 & 100 & 100 \\
\hline 0 & 363 & 14 & 26 \\
1 & 757 & 30 & 36 & 26 \\
2 or more & 767 & 30 & 31 \\
\hline & 658 & 26 & 25 & 18 \\
\hline
\end{tabular}

Table 2. Modal split by survey's source

\begin{tabular}{|c|c|c|c|c|c|c|c|c|c|c|}
\hline \multirow[t]{2}{*}{ Source } & \multicolumn{2}{|c|}{ Flyers in traffic } & \multicolumn{2}{|c|}{ Municipality } & \multicolumn{2}{|c|}{ Social media } & \multicolumn{2}{|c|}{ Street interception } & \multicolumn{2}{|c|}{ Total } \\
\hline & $\mathrm{N}$ & $\%$ & $\mathrm{~N}$ & $\%$ & $\mathrm{~N}$ & $\%$ & $\mathrm{~N}$ & $\%$ & $\mathrm{~N}$ & $\%$ \\
\hline Bicycle & 402 & 26 & 172 & 11 & 2034 & 22 & 2212 & 36 & 4820 & 26 \\
\hline Bicycle + Transit & 59 & 4 & 33 & 2 & 418 & 4 & 244 & 4 & 754 & 4 \\
\hline Bus & 126 & 8 & 151 & 10 & 752 & 8 & 419 & 7 & 1448 & 8 \\
\hline Bus + Metro & 142 & 9 & 153 & 10 & 900 & 10 & 1037 & 17 & 2232 & 12 \\
\hline Car & 301 & 19 & 426 & 28 & 1392 & 15 & 609 & 10 & 2728 & 15 \\
\hline Metro & 195 & 13 & 148 & 10 & 1416 & 15 & 919 & 15 & 2678 & 14 \\
\hline Motorcycle & 4 & 0 & 12 & 1 & 50 & 1 & 27 & 0 & 93 & 1 \\
\hline Taxi & 100 & 6 & 115 & 8 & 784 & 8 & 184 & 3 & 1183 & 6 \\
\hline Walking & 218 & 14 & 287 & 19 & 1586 & 17 & 447 & 7 & 2538 & 14 \\
\hline Total & 1547 & 100 & 1497 & 100 & 9332 & 100 & 6098 & 100 & 18474 & 100 \\
\hline
\end{tabular}

The second part of the survey contained questions that allow us to understand the reasons that keep some people away from cycling and those that motivate other people to do it. This type of question consisted of different statements where the respondents would use a Likert scale from 1 to 5 to indicate their agreement level; where 1 means a strong disagreement and 5 means a strong agreement.

Among the reasons to not use a bicycle collected in the survey, we found that the main obstacles are the absence of cycle paths along the route and the concern to be involved in an accident. Other less- 
frequent reasons were an excessive trip length or travel time and the difficulty to find a place to park their bikes or change clothes at the destination. However, the mean and mode response to these later questions was close to "neutral," indicating that they are not strong deterrents. This allows us to determine the key variables to consider in our models, such as the presence of cycle paths and the presence of heavy vehicles (buses) on the streets.

For the people who use the bicycle for some of their commuting trips, we observed the presence of cycle paths as an incentive to do it. Most of them argue they would ride their bikes more often if they had more and better bicycle infrastructure, as well as more and safer bicycle parking in their destination. Finally, those who ride their bikes on a regular basis declare that they mainly do it because it is cheaper and faster, with the presence of cycle paths or bike lanes as a clear additional incentive or facilitator. Most of them disagree with the statement "there is a safe place to park my bicycle," which might imply that, once a person becomes a frequent user, this isn't an important barrier for cycling.

The last part of the survey contains several questions about the perceived travel experience, that were used as psychometric indicators for the latent variables in our modeling framework. We asked how expeditious, pleasant, gratifying, and safe they considered their trip experience (in a likert scale from 1 to 5). In further analysis we will only consider the former three, since safety was not correlated with satisfaction after a factor analysis. By isolating women and men that report most of their trips made by bicycle, we found that male cyclists tend to consider their trips to be more expeditious, pleasant, and gratifying than female cyclists. Overall, regardless of gender, cyclists report a better experience in general in comparison with non-cyclists, as seen in Figure 4 which presents the distribution obtained for each indicator. To facilitate the comparison between curves a continuous smooth curve across the obtained values is displayed.
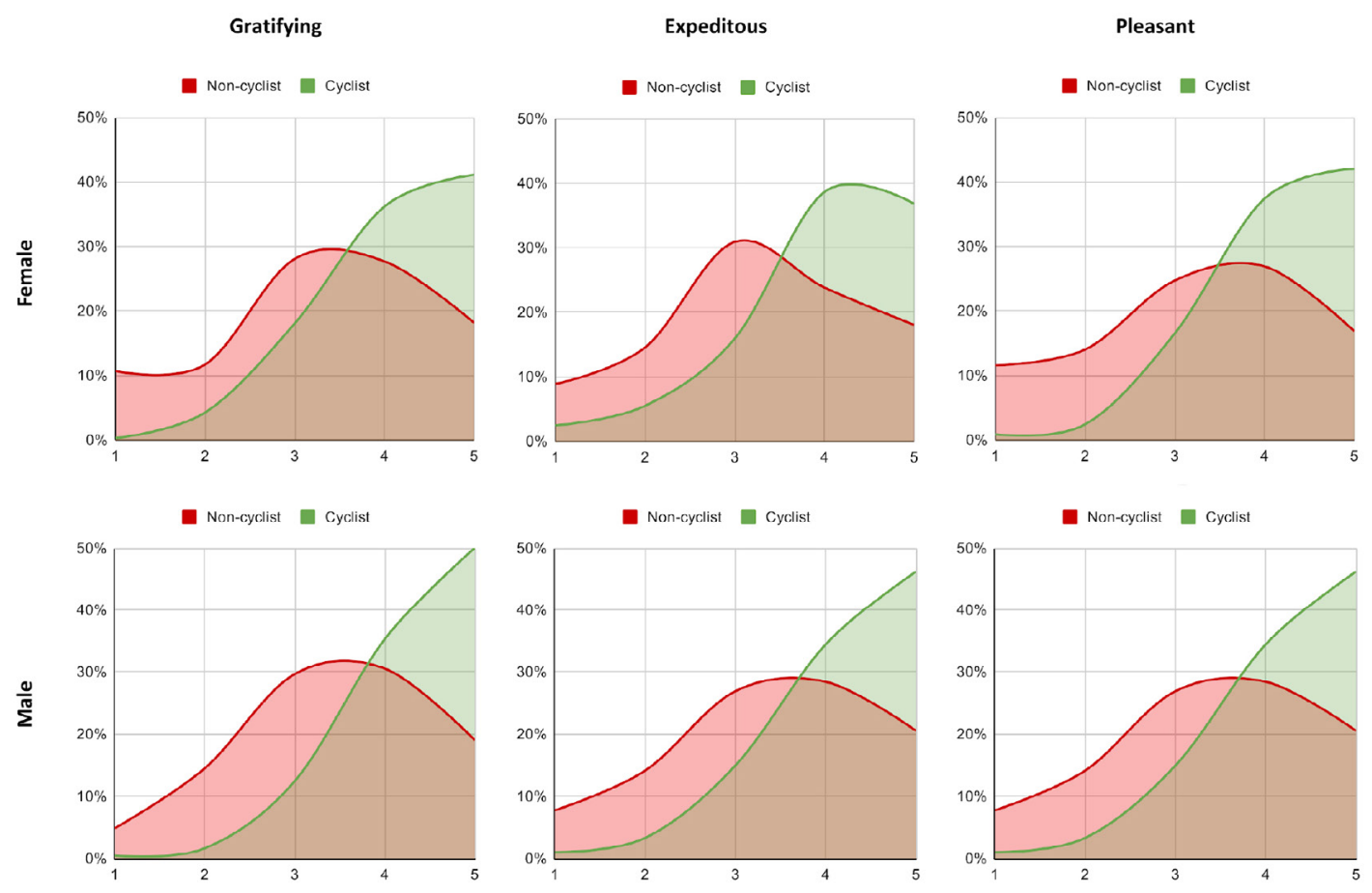

Figure 4. Responses to the perceptual indicators by mode and gender 


\section{$4 \quad$ Methodology}

We propose to use a hybrid ordered logit model to measure the relation of weekly cycling frequency and built environment attributes, socioeconomic characteristics and a latent variable of perceived satisfaction. This model is coherent with the ordinal nature of the dependent variable and the introduction of a latent variable allows us to understand how subjective factors influence cycling behavior among different individuals. First, we estimate a model for satisfaction by chosen transport mode, therefore identifying specifications that are good candidates for the latent variable. Then, we simultaneously estimate a hybrid model for cycling frequency, with a latent variable for cyclist's satisfaction.

\subsection{Modelling satisfaction by mode}

We assume that subjective perceptions can be modeled through latent variables, following previous studies in several fields such as engineering (Golob, 2003; Walker \& Ben-Akiva, 2002) and psychology (Bollen, 2002; Borsboom, Mellenbergh, \& van Heerden, 2003). This framework (Figure 5, top), allows us to determine which observable variables explain the perception of satisfaction whereas this latent variable explains the indicators of how pleasant, expeditious and gratifying, is the commuting experience.

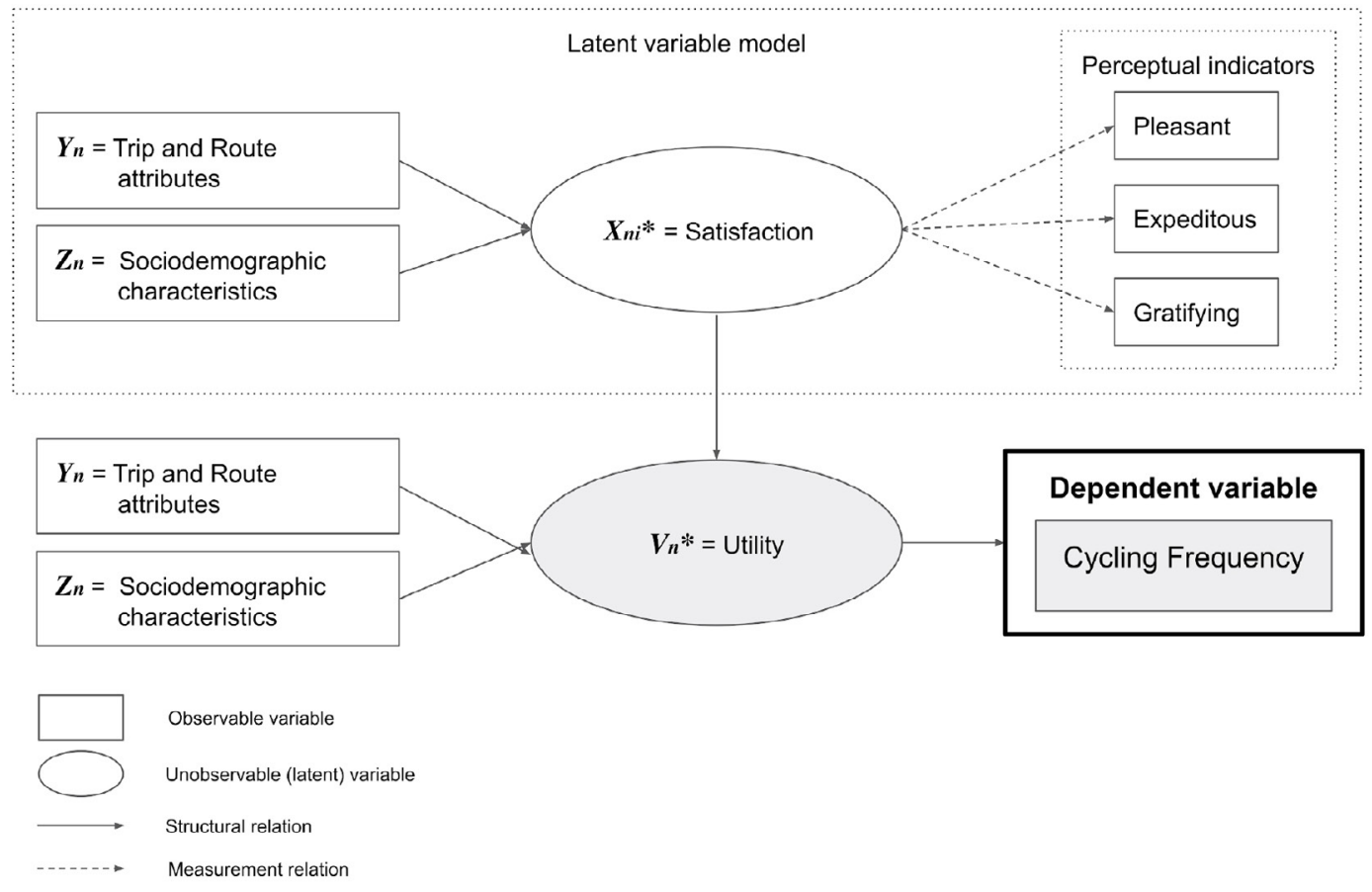

Figure 5. The hybrid logit modeling framework

We assume that the satisfaction experienced by a traveler can be modeled as a function of the built environment along the route, trip attributes, and individual characteristics. Thus, we formulate a structural equation for the satisfaction variable for each mode m, as follows:

$X_{n m}=\left(\lambda_{m} y_{n}+\beta_{m} z_{n}\right) M_{n m}$ 
where $X_{n m}$ is the latent satisfaction, $y_{n}$ is a vector of attributes of the trip and the built environment along the route, $z_{n}$ is the vector of socio-demographic characteristics of the individual and $\lambda_{m}$ and $\beta_{m}$ are mode-specific vectors of parameters to be estimated. The term $M_{n m}$ is the dummy variable defined by equation (1).

The observed responses to the perceptual questions $\left(I_{k n m}\right)$, where $k$ refers to the indicator type (pleasant, expedited or gratifying), are incorporated through a measurement equation $\left(\hat{I}_{k n m}\right)$ which is a function of the latent variable $X_{n m}$, a set of parameters $\left(a_{k m}\right.$ and $\left.b_{k m}\right)$ and an error term $\epsilon_{k n m}$ :

$\hat{I}_{k n m}=a_{k m}+b_{k m} X_{n m}+\epsilon_{k n m}$

In order to have an ordered probit model for the rate of each indicator, we assume the error term $\epsilon_{k n m}$ follows a normal $\left(N\left(0, \sigma_{k}\right)\right)$ distribution, and that the observed response to an indicator from an individual $I_{k n m}$ can be associated with equation (3) as follows:

$I_{k n m}=1$ if $\hat{I}_{k n m} \leq \mu_{1}$

$I_{k n m}=2$ if $\mu_{0}<\hat{I}_{k n m} \leq \mu_{2}$

$I_{k n m}=3$ if $\mu_{1}<\hat{I}_{k n m} \leq \mu_{3}$

$I_{k n m}=J_{k n}$ if $\mu_{j-1}<\hat{I}_{k n m}$

where $\mu_{m j}$ are thresholds of achieved utility yet to be estimated. In our case, $I_{k n m}$ goes from 1 to 5 , indicating the rating level of how pleasant, expedited, and gratifying is the commuting experience. We assume the distribution is symmetrical and, therefore, the thresholds can be defined as a function of mode-specific parameters $\delta_{m}$ yet to be estimated, as follows:

$\mu_{m 1}=-\delta_{m 1}-\delta_{m 2}$

$\mu_{m 2}=-\delta_{m 1}$

$\mu_{m 3}=\delta_{m 1}$

$\mu_{m 4}=\delta_{m 1}+\delta_{m 2}$

Therefore, the probability of an individual rating at $\mathrm{J}_{\mathrm{kn}}$ any indicator $\mathrm{I}_{\mathrm{knm}}$ can be written as follows:

$P_{n}\left(I_{k n m}=J_{k n}\right)=F\left(\frac{\mu_{m j}-a_{k m}+b_{k} X_{n m}}{\sigma_{k m}}\right)-F\left(\frac{\mu_{m j-1}-a_{k m}+b_{k m} X_{n m}}{\sigma_{k m}}\right) \quad \forall k, n, m$

Where $F$ is the cumulative distribution function of the Normal distribution. All parameters can be estimated by maximizing the likelihood of all the observed answers to indicators

$L=\prod_{k n m} P_{n}\left(I_{k n m}=J_{k n}\right)^{M_{n m}}$

Where $J_{k n}$ is the answer provided by individual $n$ to indicator $k$ 


\subsection{Hybrid Ordered Logit model: Frequency of cycling commute and satisfaction}

An ordered logit model is used to model weekly cycling frequency. We include the latent variable of perceived satisfaction, adding a normal-distributed error term $\varepsilon\left(X_{n m}{ }^{*}=X_{n m}+\varepsilon_{n m}\right)$, as an explanatory variable in the individual utility $\left(V_{n}\right)$ associated to the frequency of cycling:

$V_{n}=\lambda^{\prime} y_{n}+\beta^{\prime} z_{n}+\gamma M_{n m^{*}} X_{n m}^{*}+\epsilon_{n}$

Where $y_{n}$ is a vector of attributes of the trip and the built environment, $z_{n}$ is the vector of socio-demographic characteristics of the individual. Subindex $\mathrm{m}^{*}$ corresponds to the bicycle and, therefore, $M_{n m^{*}}$ is a dummy variable indicating if the user is a cyclist (see eq 1 ) and the latent variable of perceived satisfaction is specific to cycling. The terms $\lambda^{\prime}, \beta^{\prime}$ and $\gamma$ are parameters to be estimated. Assuming a Gumbel distribution for the error term of (8), the probability of an individual cycling with a frequency $(f)$ of $w$ days a week can be written as follows:

$$
P_{n m^{*}}\left(f=w \mid X_{n m^{*}}{ }^{*}\right)=\frac{1}{\frac{1+\exp \left(-\rho_{w}+\lambda^{\prime} y_{n}+\beta^{\prime} z_{n}+\gamma M_{n m^{*}} X_{n m^{*}}\right)}{1+\exp \left(-\rho_{w-1}+\lambda^{\prime} y_{n}+\beta^{\prime} z_{n}+\gamma M_{n m^{*}} X_{n m^{*}}\right)}}-
$$

where $\rho_{w}$ is a utility threshold associated to the weekly cycling frequency $w$, to be estimated. Because of the normal-distributed error term $\left(\varepsilon_{n m}\right)$ in the latent variable, the joint probability of and individual cycling with a frequency $w$ and providing answers $J_{k}$ to the indicators, needs to be integrated over the distribution of the error term of the latent variable, as follows:

$P_{n m^{*}}\left(f=w, I_{k n m^{*}}=J_{k n}\right)=\int P_{n m^{*}}\left(f=w \mid X_{n m}^{*}\right) \prod_{k} P_{n}\left(I_{k n m^{*}}=J_{k n}\right){ }^{M n m^{*}} f\left(X_{n m^{*}}\right) d X_{n m^{*}} *$

From Eq. (10) a maximum log-likelihood function can be derived and maximized in order to estimate the parameters $\beta, \lambda$, $\gamma$ and the thresholds $\rho$.

\section{$5 \quad$ Results}

In this section, the results of the calibration of both models are analyzed. First, we isolated the latent variables and estimated the satisfaction model for each transport mode independently, in order to understand how people experience satisfaction associated with their most usual transport mode (see section 4.1). Second, we estimate the hybrid logit model described in section 4.2 to measure the role played by several variables in the frequency of cycling, including a latent variable of satisfaction for cyclists. All the estimations were made using PandasBiogeme (Bierlaire, 2018b). Additional modelling details about the way the latent class models were implemented can be found in Bierlaire (2018a).

\subsection{Satisfaction by mode}

We estimate the model described by equation (6) for specific commuting modes: pedestrians, cyclists, car drivers, and public transport users. We tested several specifications and ended up with three explanatory variables that are common to every mode: trip length, gender, and frequency (the number of trips made in a week in the corresponding mode). 
While we recognize the limitations of our framework to explain satisfaction using the same indicators for each mode of transport, the main objective is to assess the satisfaction of cyclists and, second, to be able to compare with other modes of transport. For the case of cyclist satisfaction, we were able to include two variables describing the environment: the presence of buses and the availability of cycle paths in the route. This last variable is included interacting with a dummy variable for gender, and the same is done with the trip length, in order to identify differences between female and male cyclists.

Interestingly, as it can be seen in Table 3, the satisfaction of cyclists and pedestrians increases when they travel more frequently, while car drivers and transit users are less satisfied if the number of trips rises up. The length of the trip has a negative effect on satisfaction for all modes, except the bicycle. For cyclists, distance has the opposite effect and longer trips increase their level of satisfaction. Although, this effect is almost completely canceled when the cyclist is female. Women are more satisfied with their travel experience when riding a bicycle in general, but they are more sensitive to longer distances than men, and they appear to be less satisfied with the presence of cycle paths in the route. While walking or driving, women show no significant difference with men, but as passengers in the public transport system, they are less comfortable.

The presence of buses in the route has a negative impact on the level of satisfaction of any kind of cyclist, but the presence of cycle paths shows an unexpected impact in satisfaction. For cyclists, in general, the availability of any kind of cycle infrastructure is positive while for females this effect is significantly lower, suggesting they are quite less satisfied than men when riding along cycle paths. 
Table 3. Satisfaction's model results

\begin{tabular}{|c|c|c|c|c|c|c|c|c|}
\hline \multirow[b]{2}{*}{ Parameter } & \multicolumn{2}{|c|}{ Cyclists (N=820) } & \multicolumn{2}{|c|}{ Drivers $(\mathrm{N}=293)$} & \multicolumn{2}{|c|}{ Pedestrians $(\mathrm{N}=107)$} & \multicolumn{2}{|c|}{ Passengers (N=693) } \\
\hline & Value & t-test & Value & t-test & Value & t-test & Value & t-test \\
\hline Constant & -0.371 & -12.1 & -0.0337 & $-1.17^{* *}$ & -0.123 & -4.53 & 0.223 & 6.62 \\
\hline Cyclepaths & 0.327 & 4.34 & -- & -- & -- & -- & -- & -- \\
\hline Cyclepath for female & -0.269 & -3.19 & -- & -- & -- & -- & -- & -- \\
\hline Buses on route & -0.102 & -6.08 & -- & -- & -- & -- & -- & -- \\
\hline Cycling experience & 0.0357 & 2.84 & -- & -- & --- & -- & --- & -- \\
\hline Female & 0.28 & 2.25 & -0.0333 & $-0.577^{* *}$ & 0.0587 & $0.491^{* *}$ & -0.302 & -6.58 \\
\hline Distance $(\mathrm{km})$ & 0.246 & 6.68 & -0.018 & -3.75 & -0.167 & -5.8 & -0.0397 & -11.2 \\
\hline Distance for female $(\mathrm{km})$ & -0.213 & -2.83 & --- & -- & --- & --- & --- & --- \\
\hline \# Cycling trips & 0.123 & 8.1 & -- & -- & --- & -- & -- & --- \\
\hline \# Car trips & -- & -- & -0.0521 & -4.06 & -- & -- & -- & -- \\
\hline \# Walking trips & --- & --- & -- & -- & 0.241 & 6.54 & -- & --- \\
\hline \# Public Transport trips & --- & --- & --- & -- & --- & -- & -0.0398 & -5.95 \\
\hline Measurement eq. & Value & t-test & Value & t-test & Value & t-test & Value & t-test \\
\hline$a_{\text {pleasant }}$ & 0.906 & 25.3 & 0.874 & 25.7 & 0.926 & 22.5 & 0.911 & 24.2 \\
\hline$a_{\text {expeditous }}$ & 0.955 & 28.9 & 1.02 & 18.8 & 0.984 & 22.7 & 0.956 & 29.8 \\
\hline$a_{\text {gratifying }}$ & 0 & fixed & 0 & fixed & 0 & fixed & 0 & fixed \\
\hline$b_{\text {pleasant }}$ & 1.1 & 14.7 & 0.539 & 3.01 & 1.11 & 5.25 & 1.24 & 13.6 \\
\hline$b_{\text {expeditous }}$ & 0.903 & 13.3 & 1.72 & 5.81 & 1.22 & 5.43 & 0.799 & 10.6 \\
\hline$b_{\text {gratifying }}$ & 0 & fixed & 0 & fixed & 0 & fixed & 0 & fixed \\
\hline$\epsilon_{\text {pleasant }}$ & 1.05 & 34.8 & 1.07 & 34.8 & 1.06 & 34.8 & 1.03 & 34.7 \\
\hline$\epsilon_{\text {expeditous }}$ & 1.05 & 34.7 & 0.998 & 34.6 & 1.02 & 34.7 & 1.07 & 34.6 \\
\hline$\epsilon_{\text {gratifying }}$ & 0 & fixed & 0 & fixed & 0 & fixed & 0 & fixed \\
\hline Thresholds & Value & t-test & Value & t-test & Value & t-test & Value & t-test \\
\hline$\delta_{1}$ & 0.693 & 39.7 & 0.631 & 39.5 & 0.631 & 39.4 & 0.685 & 39.5 \\
\hline$\delta_{2}$ & 0.896 & 40.5 & 0.813 & 40.5 & 0.817 & 40.5 & 0.871 & 40.5 \\
\hline Initial Log Likelihood & & & & & & & & -58717.79 \\
\hline Final Log Likelihood & & & & & & & & -37690 \\
\hline Rho Square & & & & & & & & 0.358 \\
\hline
\end{tabular}

\subsection{Frequency of cycling as a function of satisfaction}

After estimating the latent variable for each transport mode, we estimated an ordered logit model for the frequency of cycle-commuting. Then we include the satisfaction for cyclists as a latent variable and estimate it simultaneously with the weekly frequency of cycling (see section 4.2). Results for both models are presented in Table 4, together with the results for cycling satisfaction from Table 3 for comparison purposes. It is important to notice that the observations considered for the frequency models include respondents from all modes, therefore many having cero trips per week by bicycle. The satisfaction latent variable, however, is included only in the utilities of bicycle users (those with $M_{n m}=1$ )and therefore is unlikely to be present for users with few trips by bicycle per week.

There are no significant differences between both frequency models, although the latent variable of 
satisfaction has a positive and significant effect, confirming that perceived satisfaction is correlated with more frequent cycling.

Age has a negative effect, meaning elders cycle less frequently. Although, the years of experience riding a bicycle has a positive impact, which means that people get used to it and develop a commuting habit.

The presence of buses in the route has a negative impact not only on satisfaction but also on the frequency of cycling. The presence of cycle paths in the route has a positive influence on frequency, so people who have more infrastructure along the route tend to commute by bicycle more often. However, in the simultaneous model the influence of cycle paths in satisfaction is positive for men while it has a negative net effect on women, which may imply they are uncomfortable riding along cycle paths during peak hours.

As it was expected, the trip length has a negative effect on frequency, but still contributes positively through satisfaction. Again, for the case of women, it has the opposite effect. Nevertheless, the net effect of trip distance over cycling commuting frequency is negative.

When analyzing the individual's occupation, students are less likely to cycle frequently than workers. Being female is also related to less frequent cycling and the number of children at home has the same effect. Finally, cyclists who own a bicycle are more frequent users in comparison with those who ride public bicycles. 
Table 4. Satisfaction's and frequency models results

\begin{tabular}{|c|c|c|c|c|c|c|}
\hline \multirow[b]{2}{*}{ Cycling Frequency } & \multicolumn{2}{|c|}{$\begin{array}{l}\text { Cycling Frequency } \\
\qquad(\mathrm{N}=2106)\end{array}$} & \multicolumn{2}{|c|}{$\begin{array}{c}\text { Cyclist's Satisfaction } \\
(\mathrm{N}=820)\end{array}$} & \multicolumn{2}{|c|}{$\begin{array}{l}\text { Frequency \& Satisfaction } \\
\qquad(N=2106)\end{array}$} \\
\hline & Value & t-test & Value & t-test & Value & t-test \\
\hline Age & -0.0347 & -4.99 & --- & --- & -0.0331 & -4.53 \\
\hline Buses on route & -0.249 & -6.76 & --- & --- & -0.144 & -3.63 \\
\hline Cyclepaths & 0.286 & 3.76 & --- & --- & 0.211 & 2.66 \\
\hline Cyclepaths for female & 0.0546 & $0.475^{* *}$ & --- & --- & 0.121 & $0.996^{* *}$ \\
\hline Distance $(\mathrm{km})$ & -0.115 & -3.03 & --- & --- & -0.0811 & -4.53 \\
\hline $\begin{array}{l}\text { Distance for female } \\
(\mathrm{km})\end{array}$ & 0.0149 & $0.515^{* *}$ & -- & -- & 0.0217 & $0.715^{* *}$ \\
\hline Cycling experience & 0.312 & 8.52 & --- & -- & 0.273 & 7.14 \\
\hline Female & -0.349 & $-1.4^{* *}$ & --- & --- & -0.352 & $-1.35^{* *}$ \\
\hline Kids at home & -0.149 & -2.04 & --- & --- & -0.169 & -2.18 \\
\hline Own bicycle & 3.85 & 21 & --- & --- & 3.85 & 19.9 \\
\hline Student & -0.75 & -3.57 & --- & -- & -0.665 & -2.99 \\
\hline Cyclist's Satisfaction & -- & -- & --- & -- & 0.795 & 9.7 \\
\hline Cyclist's Satisfaction & Value & t-test & Value & t-test & Value & t-test \\
\hline Constant & --- & -- & -0.371 & -12.1 & -0.896 & $0^{* *}$ \\
\hline Buses on route & -- & -- & -0.102 & -6.08 & -0.0719 & -2.27 \\
\hline Female & --- & -- & 0.28 & 2.25 & 1.1 & 5.3 \\
\hline Cyclepaths & -- & -- & 0.327 & 4.34 & 0.161 & 3.02 \\
\hline Cyclepaths for female & --- & -- & -0.269 & -3.19 & -0.249 & -2.96 \\
\hline Distance $(\mathrm{km})$ & -- & -- & 0.246 & 6.68 & 0.508 & 8.32 \\
\hline $\begin{array}{l}\text { Distance for female } \\
(\mathrm{km})\end{array}$ & --- & -- & -0.213 & -2.83 & -0.548 & -4.38 \\
\hline Cycling experience & -- & -- & 0.0357 & 2.84 & 0.108 & 4.9 \\
\hline \# Cycling trips & --- & -- & 0.123 & 8.1 & -- & -- \\
\hline Thresholds & Value & t-test & Value & t-test & Value & t-test \\
\hline$\rho_{1}$ & 0 & $0^{* *}$ & --- & -- & -0.0033 & $0^{* *}$ \\
\hline$\rho_{2}$ & 0.627 & 8.87 & -- & -- & 0.6607 & 8.89 \\
\hline$\rho_{3}$ & 1.138 & 8.82 & -- & -- & 1.2337 & 8.82 \\
\hline$\rho_{4}$ & 1.646 & 9.8 & -- & -- & 1.8087 & 9.75 \\
\hline$\rho_{5}$ & 2.229 & 11.7 & -- & -- & 2.4577 & 11.6 \\
\hline$\delta_{1}$ & -- & -- & 0.693 & 39.7 & 0.432 & 40 \\
\hline$\delta_{2}$ & -- & -- & 0.896 & 40.5 & 0.58 & 40 \\
\hline Initial Log Likelihood & & -3406.4 & & -58717.79 & & -3776.2 \\
\hline Final Log Likelihood & & -1540.6 & & -37690 & & -1737.3 \\
\hline Rho Square & & 0.548 & & 0.358 & & 0.54 \\
\hline
\end{tabular}




\section{Discussion}

From the analysis of perceived satisfaction for each transport mode, we confirm that active transport modes, such as walking and biking, are related with a predominant feeling of satisfaction as previous studies have partially found (Morris \& Guerra, 2015; Rissel et al., 2016; Willis et al., 2013). This can be confirmed because satisfaction increases when people commute more often in active modes and decreases with the number of trips made by car or public transport. There might be an intrinsic pleasure in the experience of commuting by bike or walking, related to the physical activity that contributes to improve health (Oja et al., 2011), but also with the satisfaction of being immune to congestion, since cyclists can easily move ahead of traffic jams.

It is unexpected that satisfaction for cyclists increases with distance, while all other commuters show a negative correlation between distance and satisfaction. This result could be explained by the pleasure of pedaling and the opportunity to exercise while commuting, therefore saving time (Olsson et al., 2013). It is also key to acknowledge that, for this sample, most of the bicycle trips are shorter than $8 \mathrm{~km}(82 \%)$, so most trips are within a 30-minute bike ride, which cyclists may consider pleasant to ride. Thus, the long trips in the sample are not necessarily too long, while short distances might not be long enough to release endorphins through physical activity. Although, it is noticeable that this effect is canceled for female cyclists. Women are less satisfied with longer trips, which was expectable considering that, in Chile, women are more likely to have a sedentary life than men (Martínez et al., 2018).

Nevertheless, even when satisfaction appears to grow with the distance, the frequency of cycling commute is lower for longer trips; which is consistent with previous research from Santiago (Oliva et al., 2017; Ortuzar et al., 2000) and other cities (Damant-Sirois \& El-Geneidy, 2015; Heinen, Maat, \& van Wee, 2013). It is interesting to notice that, even when the frequency is considered (either by including it directly in the latent variable specification or by estimating it simultaneously), trip distance still has a positive effect on satisfaction for cyclists, suggesting these are independent effects. This is probably different for longer trips, but the revealed data gathered in this study does not allow us to measure it.

Another remarkable finding is that women are equally satisfied than men when driving or walking, but they are less satisfied than men when using public transport. This result might be explained because of the agglomerations and potential exposure to sexual harassment, which are issues in Santiago's public transport system.

When analyzing the influence of street attributes in perceived satisfaction, we tried several specifications including the number of car lanes, the presence of parking spots at the curbside and the existence of trees along the street. None of them were statistically significant and, therefore, are not included in the final model estimation, although we propose that future research should address these variables. The only two attributes that turned out to be significant were the presence of buses and the availability of cycling infrastructure, which are included in the structural equation for cyclists' satisfaction.

The former has a negative impact on satisfaction since cyclists are forced to deal with heavy vehicles and risky maneuvers. This is consistent with previous literature (Dill \& Voros, 2007; Rossetti et al., 2018; Rosetti et al., 2019) finding that cyclists have a negative perception of high-traffic intensity roads. The latter has a positive impact on cyclist's satisfaction, as we expected, but for the case of female cyclists, the effect is slightly negative. At first sight, this is a counterintuitive result, but it could be explained by crowding conditions in Providencia's cycle paths during peak hours, which induces competitiveness and risky maneuvers among male cyclists. Additionally, cycling infrastructure in Santiago is far from having the quality standard suggested by most design manuals, so it may require some skills to ride along them, especially at poorly resolved intersections and junctions, which may induce women to avoid them at the rush hour. This is a relevant result for public policy as it suggests that the current standard of Santiago's 
bicycle infrastructure is not attractive enough to encourage more women to commute by bicycle on a daily basis.

Regarding cycle-commuting frequency, perceived satisfaction appears to be a very relevant variable. When cyclists experience satisfaction in their commuting experience they are more likely to do it frequently. This enforces the idea of focusing on how the built environment and street attributes are perceived by different types of commuters, such as women or elders. Understanding built-environmentdriven satisfaction could be, therefore, useful to inform the design process of cycling infrastructure networks, in order to attract more users.

Considering the directly observed variables that influence cycle-commuting frequency, we found that the number of cars at home and slope are not significant (therefore not shown in the Tables presenting results), which contradicts part of the literature (Oliva et al, 2017; Cervero et al, 2009). For this sample, an important portion of cycle-commuters have a car at home but that does not seem to influence the decision to ride a bicycle or not. It is important to consider that this study was carried out in a central district, presenting high congestion during peak periods, so driving could be an inconvenient alternative for commuters. Likewise, the slope in the area where the case study is focused is never above $1 \%$, which explains the lack of relevance for this variable. However, in urban contexts with higher slopes, we would expect slope to affect cycling frequency.

The presence of buses on the route not only decreases satisfaction but also impacts cycling frequency confirming the importance of delivering segregated infrastructure in main roads, that provide safety and comfort for every type of cyclist, separated from high-traffic and heavy vehicles. Even when the contribution of cycling infrastructure in satisfaction is uneven for male and female cyclists when it comes to frequency their contribution is clearly positive. This means that delivering infrastructure is likely to induce more frequent cycle commuters but we are failing, somehow, to deliver the level of comfort that would encourage women to cycle and to do it with joy. We think this is a relevant contribution, providing additional evidence to encourage policymakers to build more infrastructure taking special care of female cyclist's requirements.

Among sociodemographic characteristics, it is noticeable that women cycle less frequently than men, suggesting that more research is needed to address specific issues and barriers that female cyclists are facing. This is an important result, that confirms -again- the necessity of building proper infrastructure that can increase the participation of women in cycling for commuting purposes. When analyzing the individual's occupation, students use their bikes less frequently than workers. This result might be surprising, but it can be explained because students in Chile have an important discount on public transport fares, so the bicycle is less cost-effective for this group than for working people.

The number of children at home has a negative impact on cycling, since taking kids to school or other activities by bike is challenging in a city with few bike lanes in a fragmented network, forcing people to ride on the street or sidewalks. Again, these results support the claim for more and better infrastructure to induce cycling among students and parents, that won't feel safe enough to travel with their kids or let them go alone to school if they have to ride on the streets without segregation.

As it was expected the frequency of cycling decreases with age (Moudon et al., 2005; Oliva et al., 2017), meaning that as people grow older they are less capable to maintain high rates of cycling in comparison with middle-aged and young adults. Last but not least, commuters who ride their own bicycles are frequent users in comparison with public bicycle users. This is an expected result and supports the idea that sharing systems are a good way to encourage new cyclists to give it a try and, hopefully, become frequent cyclists in the future. 


\section{$7 \quad$ Conclusions}

Overall, our study contributes new insights to understand what are the key factors that motivate people to ride a bicycle for commuting purposes in a developing country city, focusing on objective attributes but also on how these factors are mediated by subjective perceptions among different types of commuters.

Among the key takeaways, it appears that cycling is an expeditious, pleasant, and gratifying mode of transport for commuting purposes at least until $8 \mathrm{~km}$. Another conclusion is that cycle infrastructure is a key factor to induce people to cycle-commute frequently, but it is also clear that male and female cyclists experience the built environment differently, and some type of facilities might not be enough to deliver a pleasant experience among women that encourage them to cycle more often.

Future research should attempt to focus on more variables from urban design and the built environment such as the availability of different types and quality of cycling infrastructure; the presence of trees or parking spots along the route, among others. It would also be an important contribution to address more specific attributes of street design, such as intersections and transitions, to evaluate their impact on female cyclists' satisfaction.

\section{Acknowledgments}

The authors gratefully acknowledge the research support provided by the Center for Sustainable Urban Development, CEDEUS (ANID/Fondap 15110020), Fondecyt (project 1180605) and ANID PhD scholarship ((21200359). We appreciate the contribution of Anibal Rojas in the first iteration of model specification. 


\section{References}

Abou-Zeid, M., Witter, R., Bierlaire, M., Kaufmann, V., \& Ben-Akiva, M. (2012). Happiness and travel mode switching: Findings from a Swiss public transportation experiment. Transport Policy, 19(1), 93-104. https://doi.org/10.1016/j.tranpol.2011.09.009

Akar, G., \& Clifton, K. J. (2009). Influence of individual perceptions and bicycle infrastructure on decision to bike. Transportation Research Record: Journal of the Transportation Research Board, 2140(1), 165-172. https://doi.org/10.3141/2140-18

Aldred, R., \& Dales, J. (2017). Diversifying and normalizing cycling in London, UK: An exploratory study on the influence of infrastructure. Journal of Transport \& Health, 4, 348-362. https://doi. org/10.1016/j.jth.2016.11.002

Bahamonde-Birke, F. J., Kunert, U., Link, H., \& Ortúzar, J. de D. (2017). About attitudes and perceptions: Finding the proper way to consider latent variables in discrete choice models. Transportation, 44(3), 475-493. https://doi.org/10.1007/s11116-015-9663-5

Bierlaire, M. (2018a). Estimating choice models with latent variables with PandasBiogeme. Retrieved from http://infoscience.epfl.ch/record/264260

Bierlaire, M. (2018b). PandasBiogeme: A short introduction (Technical report TRANSP-OR 181219). Lausanne, Switzerland: Transport and Mobility Laboratory, ENAC, EPFL, Bioegeme.

Bollen, K. A. (2002). Latent variables in psychology and the social sciences. Annual Review of Psychology, 53(1), 605-634. https://doi.org/10.1146/annurev.psych.53.100901.135239

Borsboom, D., Mellenbergh, G. J., \& van Heerden, J. (2003). The theoretical status of latent variables. Psychological Review, 110(2), 203-219. https://doi.org/10.1037/0033-295X.110.2.203

Broach, J., Dill, J., \& Gliebe, J. (2012). Where do cyclists ride? A route choice model developed with revealed preference GPS data. Transportation Research Part A: Policy and Practice, 46(10), 1730-1740. https://doi.org/10.1016/j.tra.2012.07.005

Buehler, R., \& Dill, J. (2015). Bikeway networks: A review of effects on cycling. Transport Reviews, 36, 9-27. https://doi.org/10.1080/01441647.2015.1069908

Buehler, R., \& Pucher, J. (2011). Sustainable transport in Freiburg: Lessons from Germany's environmental capital. International Journal of Sustainable Transportation, 5(1), 43-70. https://doi. org/10.1080/15568311003650531

Cervero, R., \& Duncan, M. (2003). Walking, bicycling, and urban landscapes: Evidence from the San Francisco Bay Area. American Journal of Public Health, 93(9), 1478-1483. https://doi.org/10.2105/ AJPH.93.9.1478

Cervero, R., Sarmiento, O. L., Jacoby, E., Gomez, L. F., \& Neiman, A. (2009). Influences of built environments on walking and cycling: Lessons from Bogotá. International Journal of Sustainable Transportation, 3(4), 203-226. https://doi.org/10.1080/15568310802178314

Cui, Y., Mishra, S., \& Welch, T. F. (2014). Land use effects on bicycle ridership: A framework for state planning agencies. Journal of Transport Geography, 41, 220-228. https://doi.org/10.1016/j.jtrangeo.2014.10.004

Damant-Sirois, G., \& El-Geneidy, A. M. (2015). Who cycles more? Determining cycling frequency through a segmentation approach in Montreal, Canada. Transportation Research Part A: Policy and Practice, 77, 113-125. https://doi.org/10.1016/j.tra.2015.03.028

de Hartog, J. J., Boogaard, H., Nijland, H., \& Hoek, G. (2010). Do the health benefits of cycling outweigh the risks? Environmental Health Perspectives, 118(8), 1109-1116. https://doi.org/10.1289/ ehp.0901747

De Vos, J. (2019). Satisfaction-induced travel behavior. Transportation Research Part F: Traffic Psychology and Behavior, 63,12-21. https://doi.org/10.1016/j.trf.2019.03.001 
De Vos, J., Schwanen, T., Van Acker, V., \& Witlox, F. (2019). Do satisfying walking and cycling trips result in more future trips with active travel modes? An exploratory study. International Journal of Sustainable Transportation, 13(3), 180-196. https://doi.org/10.1080/15568318.2018.1456580

Dickinson, J. E., Kingham, S., Copsey, S., \& Hougie, D. J. P. (2003). Employer travel plans, cycling and gender: Will travel plan measures improve the outlook for cycling to work in the UK? Transportation Research Part D: Transport and Environment, 8(1), 53-67. https://doi.org/10.1016/S13619209(02)00018-4

Dill, J., \& McNeil, N. (2013). Four types of cyclists? Examination of typology for better understanding of bicycling behavior and potential. Transportation Research Record: Journal of the Transportation Research Board, 2387(1), 129-138. https://doi.org/10.3141/2387-15

Dill, J., \& Voros, K. (2007). Factors affecting bicycling demand: Initial survey findings from the Portland region. Retrieved from https://doi.org/10.3141/2031-02

Ettema, D., Gärling, T., Eriksson, L., Friman, M., Olsson, L. E., \& Fujii, S. (2011). Satisfaction with travel and subjective well-being: Development and test of a measurement tool. Transportation Research Part F: Traffic Psychology and Behavior, 14(3), 167-175. https://doi.org/10.1016/j.trf.2010.11.002

Fernández-Heredia, Á., Monzón, A., \& Jara-Díaz, S. (2014). Understanding cyclists' perceptions, keys for a successful bicycle promotion. Transportation Research Part A: Policy and Practice, 63, 1-11. https://doi.org/10.1016/j.tra.2014.02.013

Fuentes, L., \& Pezoa, M. (2018). Nuevas geografías urbanas en Santiago de Chile 1992-2012. Entre la explosión y la implosión de lo metropolitano. Revista de Geografía Norte Grande, 70, 131-151. https://doi.org/10.4067/S0718-34022018000200131

Gatersleben, B., \& Appleton, K. M. (2007). Contemplating cycling to work: Attitudes and perceptions in different stages of change. Transportation Research Part A: Policy and Practice, 41(4), 302-312. https://doi.org/10.1016/j.tra.2006.09.002

Gatersleben, B., \& Uzzell, D. (2007). Affective appraisals of the daily commute: Comparing perceptions of drivers, cyclists, walkers, and users of public transport. Environment and Behavior, 39(3), 416-431. https://doi.org/10.1177/0013916506294032

Golob, T. F. (2003). Structural equation modeling for travel behavior research. Transportation Research Part B: Methodological, 37(1), 1-25. https://doi.org/10.1016/S0191-2615(01)00046-7

Guevara, C. A., Tirachini, A., Hurtubia, R., \& Dekker, T. (2020). Correcting for endogeneity due to omitted crowding in public transport choice using the multiple indicator solution (MIS) method. Transportation Research Part A: Policy and Practice, 137, 472-484. https://doi.org/10.1016/j. tra.2018.10.030

Gutiérrez, M., Hurtubia, R., \& Ortúzar, J. de D. (2020). The role of habit and the built environment in the willingness to commute by bicycle. Travel Behavior and Society, 20, 62-73. https://doi. org/10.1016/j.tbs.2020.02.007

Handy, S. L., \& Xing, Y. (2011). Factors correlated with bicycle commuting: A study in six small U.S. cities. International Journal of Sustainable Transportation, 5(2), 91-110. https://doi. org/10.1080/15568310903514789

Heinen, E., Maat, K., \& van Wee, B. (2013). The effect of work-related factors on the bicycle commute mode choice in the Netherlands. Transportation, 4O(1), 23-43. https://doi.org/10.1007/s11116012-9399-4

Heinen, E., van Wee, B., \& Maat, K. (2009). Commuting by bicycle: An overview of the literature. Transport Reviews, 30, 59-96. https://doi.org/10.1080/01441640903187001

Hunt, J. D., \& Abraham, J. E. (2007). Influences on bicycle use. Transportation, 34(4), 453-470. https://doi.org/10.1007/s11116-006-9109-1 
Krizek, K. J., Barnes, G., \& Thompson, K. (2009). Analyzing the effect of bicycle facilities on commute mode share over time. Journal of Urban Planning and Development, 135(2), 66-73. https://doi. org/10.1061/(ASCE)0733-9488(2009)135:2(66)

Lowry, M. B., Furth, P., \& Hadden-Loh, T. (2016). Prioritizing new bicycle facilities to improve lowstress network connectivity. Transportation Research Part A: Policy and Practice, 86, 124-140. https:// doi.org/10.1016/j.tra.2016.02.003

Ma, L., \& Dill, J. (2015). Associations between the objective and perceived built environment and bicycling for transportation. Journal of Transport \& Health, 2(2), 248-255. https://doi.org/10.1016/j. jth.2015.03.002

Macmillan, A., Connor, J., Witten, K., Kearns, R., Rees, D., \& Woodward, A. (2014). The societal costs and benefits of commuter bicycling: Simulating the effects of specific policies using system dynamics modeling. Environmental Health Perspectives, 122(4), 335-344. https://doi.org/10.1289/ ehp. 1307250

Martínez, M. A., Leiva, A. M., Petermann, F., Garrido, A., Díaz, X., Álvarez, C. .. \& Celis, C. (2018). Factores asociados a sedentarismo en Chile: Evidencia de la Encuesta Nacional de Salud 2009-2010. Revista Médica de Chile, 146(1), 22-31. https://doi.org/10.4067/s0034-98872018000100022

MIDESO. (2017). Encuesta CASEN. Ministerio de Desarrollo Social, Chile. Retrieved from: http:// observatorio.ministeriodesarrollosocial.gob.cl/casen-multidimensional/casen/casen_2017.php

Morris, E. A., \& Guerra, E. (2015). Mood and mode: Does how we travel affect how we feel? Transportation, 42(1), 25-43. https://doi.org/10.1007/s11116-014-9521-x

Moudon, A. V., Lee, C., Cheadle, A. D., Collier, C. W., Johnson, D., Schmid, T. L., \& Weather, R. D. (2005). Cycling and the built environment, a US perspective. Transportation Research Part D: Transport and Environment, 10(3), 245-261. https://doi.org/10.1016/j.trd.2005.04.001

Muñoz, B., Monzon, A., \& López, E. (2016a). Transition to a cyclable city: Latent variables affecting bicycle commuting. Transportation Research Part A: Policy and Practice, 84, 4-17. https://doi. org/10.1016/j.tra.2015.10.006

Muñoz, B., Monzon, A., \& Daziano, R. A. (2016b). The increasing role of latent variables in modelling bicycle mode choice. Transport Reviews, 36(6), 737-771. https://doi.org/10.1080/01441647.2016 .1162874

Noland, R. B., \& Kunreuther, H. (1995). Short-run and long-run policies for increasing bicycle transportation for daily commuter trips. Transport Policy, 2(1), 67-79. https://doi.org/10.1016/0967070X(95)93248-W

Ogilvie, D., Egan, M., Hamilton, V., \& Petticrew, M. (2004). Promoting walking and cycling as an alternative to using cars: Systematic review. BMJ, 329(7469), 763. https://doi.org/10.1136/ bmj.38216.714560.55

Oja, P., Titze, S., Bauman, A., de Geus, B., Krenn, P., Reger-Nash, B., \& Kohlberger, T. (2011). Health benefits of cycling: A systematic review: Cycling and health. Scandinavian Journal of Medicine \& Science in Sports, 21(4), 496-509. https://doi.org/10.1111/j.1600-0838.2011.01299.x

Oliva, I., Galilea, P., \& Hurtubia, R. (2017). Identifying cycling-inducing neighborhoods: A latent class approach. International Journal of Sustainable Transportation, 12, 701-713. https://doi.org/10.1080 /15568318.2018.1431822

Olsson, L. E., Gärling, T., Ettema, D., Friman, M., \& Fujii, S. (2013). Happiness and satisfaction with work commute. Social Indicators Research, 111(1), 255-263.

Ortúzar, J. de D., Iacobelli, A., \& Valeze, C. (2000). Estimating demand for a cycle-way network. Transportation Research Part A: Policy and Practice, 34(5), 353-373. https://doi.org/10.1016/S09658564(99)00040-3 
Palma, D., Ortúzar, J. de D., Rizzi, L. I., Guevara, C. A., Casaubon, G., \& Ma, H. (2016). Modelling choice when price is a cue for quality: A case study with Chinese consumers. Journal of Choice Modelling, 19, 24-39. https://doi.org/10.1016/j.jocm.2016.06.002

Pritchard, R. (2018). Revealed preference methods for studying bicycle route choice-A systematic review. International Journal of Environmental Research and Public Health, 15(3), 470. https://doi. org/10.3390/ijerph15030470

Pucher, J., Buehler, R., \& Seinen, M. (2011). Bicycling renaissance in North America? An update and re-appraisal of cycling trends and policies. Transportation Research Part A: Policy and Practice, 45(6), 451-475. https://doi.org/10.1016/j.tra.2011.03.001

Rissel, C., Crane, M., Wen, L. M., Greaves, S., \& Standen, C. (2016). Satisfaction with transport and enjoyment of the commute by commuting mode in inner Sydney: Satisfaction and enjoyment by commute mode. Health Promotion Journal of Australia, 27(1), 80-83. https://doi.org/10.1071/ HE15044

Rossetti, T., Guevara, C. A., Galilea, P., \& Hurtubia, R. (2018). Modeling safety as a perceptual latent variable to assess cycling infrastructure. Transportation Research Part A: Policy and Practice, 111, 252-265. https://doi.org/10.1016/j.tra.2018.03.019

Rossetti, T., Saud, V., \& Hurtubia, R. (2019). I want to ride it where I like: Measuring design preferences in cycling infrastructure. Transportation, 46(3), 697-718. https://doi.org/10.1007/s11116017-9830-y

Sallis, J. F., Conway, T. L., Dillon, L. I., Frank, L. D., Adams, M. A., Cain, K. L., \& Saelens, B. E. (2013). Environmental and demographic correlates of bicycling. Preventive Medicine, 57(5), 456460. https://doi.org/10.1016/j.ypmed.2013.06.014

SECTRA. (2013). Análisis del comportamiento de la demanda de infraestructura especializada para bicicletas. Ministerio de Transporte y Telecomunicaciones, Santiago. Retrieved from http://www. sectra.gob.cl/biblioteca/detalle1.asp?mfn=3121

SECTRA. (2015). Encuesta Origen Destino de Santiago 2012. Ministerio de Transporte y Telecomunicaciones, Santiago. Retrieved from http://www.sectra.gob.cl/biblioteca/biblioteca.asp

Stinson, M. A., \& Bhat, C. R. (2003). Commuter bicyclist route choice: Analysis using a stated preference survey. Transportation Research Record: Journal of the Transportation Research Board, 1828(1), 107-115. https://doi.org/10.3141/1828-13

Stinson, M. A., \& Bhat, C. R. (2004). Frequency of bicycle commuting: Internet-based survey analysis. Transportation Research Record: Journal of the Transportation Research Board, 1878(1), 122-130. https://doi.org/10.3141/1878-15

Stinson, M. A., \& Bhat, C. R. (2005). A comparison of the route preferences of experienced and inexperienced bicycle commuters (No. 05-1434).

Walker, J., \& Ben-Akiva, M. (2002). Generalized random utility model. Mathematical Social Sciences, 43(3), 303-343. https://doi.org/10.1016/S0165-4896(02)00023-9

Wang, H., Palm, M., Chen, C., Vogt, R., \& Wang, Y. (2016). Does bicycle network level of traffic stress (LTS) explain bicycle travel behavior? Mixed results from an Oregon case study. Journal of Transport Geography, 57, 8-18. https://doi.org/10.1016/j.jtrangeo.2016.08.016

Wardman, M., Tight, M., \& Page, M. (2007). Factors influencing the propensity to cycle to work. Transportation Research Part A: Policy and Practice, 41(4), 339-350. https://doi.org/10.1016/j. tra.2006.09.011

Willis, D. P., Manaugh, K., \& El-Geneidy, A. (2013). Uniquely satisfied: Exploring cyclist satisfaction. Transportation Research Part F: Traffic Psychology and Behavior, 18, 136-147. https://doi. org/10.1016/j.trf.2012.12.004 
Ye, R., \& Titheridge, H. (2017). Satisfaction with the commute: The role of travel mode choice, built environment and attitudes. Transportation Research Part D: Transport and Environment, 52, 535 547. https://doi.org/10.1016/j.trd.2016.06.011 